\title{
The extent of the psychological impairment of prosthodontic outpatients at a German University Hospital
} Michelle A Ommerborn ${ }^{1}$, Alfons Hugger ${ }^{2}$, Johannes Kruse ${ }^{3}$, Jörg GK Handschel ${ }^{4}$, Rita A Depprich*4, Ulrich Stüttgen², Stefan Zimmer ${ }^{5}$ and Wolfgang HM Raab ${ }^{1}$

Address: ${ }^{1}$ Department of Operative and Preventive Dentistry and Endodontics, Heinrich-Heine-University Düsseldorf, Moorenstr. 5, 40225 Düsseldorf, Germany, ${ }^{2}$ Department of Prosthodontics, Heinrich-Heine-University Düsseldorf, Moorenstr. 5, 40225 Düsseldorf, Germany, ${ }^{3}$ Clinical Institute of Psychosomatic Medicine and Psychotherapy, Heinrich-Heine-University Düsseldorf, Moorenstr. 5, 40225 Düsseldorf, Germany, ${ }^{4}$ Department of Cranio- and Maxillofacial Surgery, Heinrich-Heine-University Düsseldorf, Moorenstr. 5, 40225 Düsseldorf, Germany and ${ }^{5}$ Department of Operative and Preventive Dentistry, University of Witten/Herdecke, Alfred-Herrhausen-Str. 50, 58448 Witten, Germany

Email: Michelle A Ommerborn - ommerborn@med.uni-duesseldorf.de; Alfons Hugger - hugger@uni-duesseldorf.de; Johannes Kruse - kruse@uni-duesseldorf.de; Jörg GK Handschel - handschel@med.uni-duesseldorf.de; Rita A Depprich* - depprich@med.uniduesseldorf.de; Ulrich Stüttgen - stuettgen@med.uni-duesseldorf.de; Stefan Zimmer - Stefan.Zimmer@uni-wh.de;

Wolfgang HM Raab - raab@med.uni-duesseldorf.de

* Corresponding author

Published: 23 October 2008

Head \& Face Medicine 2008, 4:23 doi:10.1186/1746-160X-4-23
Received: 26 September 2007

Accepted: 23 October 2008

This article is available from: http://www.head-face-med.com/content/4/I/23

(c) 2008 Ommerborn et al; licensee BioMed Central Ltd.

This is an Open Access article distributed under the terms of the Creative Commons Attribution License (http://creativecommons.org/licenses/by/2.0), which permits unrestricted use, distribution, and reproduction in any medium, provided the original work is properly cited.

\begin{abstract}
Background: Psychological factors are not only important in patients with temporomandibular disorders (TMDs), but also in patients suffering from tooth loss and/or in those awaiting prosthodontic care with fixed or removable dentures as several authors emphasize. The purpose of the present prospective observational study was to compare prosthodontic outpatients of the Department of Prosthodontics at the University of Duesseldorf and patients seeking care at the TMD/Orofacial Pain Outpatient Clinic (TMD/OFPOC) at the same university with respect to sociodemographic data, self-reported somatic complaints, and psychological impairment.
\end{abstract}

Methods: A total of 234 patients received two self-administered questionnaires including the Symptom-CheckList. Complete data have been obtained from 65 prosthodontic outpatients and 60 patients of the TMD/OFPOC.

Results: Results indicated statistically significant group differences regarding sociodemographic data and somatic complaints. Concerning the latter, in II of the $2 \mathrm{I}$ items, groups differed significantly and confirmed the absence of any mixing between the two outpatient clinics. Although the evaluation of psychological impairment revealed no significant group differences, in $21.9 \%$ of the prosthodontic outpatients and in $22.0 \%$ of the patients from the TMD/OFPOC, the extent of the determined psychological impairment was similar to that of psychotherapeutic outpatients; in $9.4 \%$ and $8.5 \%$ it was similar to that of psychotherapeutic inpatients, respectively.

Conclusion: Within the limitations of this study, in approximately one third of the evaluated patients of both the prosthodontic outpatient clinic and the TMD/OFPOC the psychological impairment reached values comparable to those of psychotherapeutic outpatients and psychotherapeutic inpatients. Therefore, the present findings emphasize the need to intensify the integration of psychosomatic aspects into dentistry and, in particular, to add psychological considerations to future German education plans. 


\section{Background}

While the prosthodontic management of patients with fixed partial dentures, removable partial dentures, and complete dentures represents a routine situation in daily dental practice, a lot of patients have difficulties adapting to the sensation of a foreign body [1]. This may be due to the fact that the oral environment is an extremely sensitive region [2] which can be affected by both physical and psychological stressors [1]. To give an example for physical impairment as a result of prosthodontic management: wearing removable partial or complete dentures often impairs masticatory function and speech transiently $[2,3]$. Further physical problems such as soreness of denturesupporting tissues, tooth movement, carious lesions at the abutment teeth [4], and temporomandibular disorders $[1,5]$ have been documented. Apart from these physical reasons that may potentially cause problems following prosthodontic management, several authors also underline the role of psychological factors in the process of accepting removable dentures and adapting to them $[3,5$ 7].

In general, psychological response to tooth loss and denture wearing may be influenced by the patient's personality and, thus, may sometimes depend less on the technical quality of the dentures [3]. For instance, one investigator found somatization to be a factor in general dental practice per se [8], whereas some researchers assumed subjective body complaints to be an indicator of somatization particularly in elderly patients [9]. Hence, a clear association between age and irreversible complications during prosthetic rehabilitation has been found [10] and, eventually, many of these patients are referred to specialized dental clinics, such as prosthodontic outpatient clinics at university hospitals.

Another group of patients that is typically referred to special university-based care clinics consists of patients suffering from temporomandibular disorders (TMDs). Although various factors, such as anatomy, trauma, pathophysiology, and psychology have been suggested to be involved in the development of TMD, the etiology has not definitely been clarified so far [11-14]. According to the literature, psychosocial factors have become a field of increasing interest. For instance, several studies have clearly indicated that compared to matched controls TMD patients had higher levels of psychological distress, including anxiety, somatization, and depression [15-17].

Considering this and the fact that typically both prosthodontic outpatient clinics and TMD/orofacial pain outpatient clinics are university-based care centers, patients in these institutions were not really found to be representative and thus cannot easily be compared with patients from a general dental practice. In particular, the extent of psychological impairment of patients seeking care at a prosthodontic outpatient clinic (POC) was regarded to be more obvious than in those patients that usually turn to their general dental practitioner. Hence, a comparison of patients of two different outpatient clinics appears to be more appropriate for the evaluation. Moreover, given the fact that these outpatient clinics take part in university education programs, potentially beneficial insights resulting from such observational investigation might have a favorable effect on future education plans. Therefore, the purpose of the present prospective observational study was to compare patients of a POC of the Department of Prosthodontics at the University of Duesseldorf with patients seeking care at the TMD/Orofacial Pain Outpatient Clinic (TMD/OFPOC) at the same university. We examined sociodemographic data, self-reported somatic complaints, and psychological impairment. The hypothesis used in this investigation was that groups differ significantly regarding their sociodemographic data and selfreported somatic complaints. Conversely, it was expected that there is no difference between both groups regarding the extent of psychological impairment.

\section{Methods \\ Sample}

Following written informed consent obtained by each patient, a total of 234 subjects, 148 females and 86 males, with a mean age of $49.24 \pm 15.73$ years (range 15 to 89 years), participated in this investigation. One hundred patients who sought care at the POC of the Department of Prosthodontics at the University of Duesseldorf were continuously recruited. This group of patients consulted the POC predominantly for detailed advice and/or treatment planning of a new prosthodontic restoration or concerning the repair of a damaged or insufficient prosthodontic restoration, and the presence of dental pain.

In addition, 134 patients seeking care at the TMD/OFPOC at the same university for the management of TMD were also included. As derived from the individual index cards, at the first appointment each patient was previously subjected to a detailed dental functional examination of the masticatory system which had been performed by one trained dentist. According to the Research Diagnostic Criteria for Temporomandibular Disorders (RDC/TMD) [18], the most frequently determined diagnoses were: myofascial pain, anterior disc displacement, arthralgia, osteoarthritis, and osteoarthrosis. Additionally, signs of bruxism have been documented using the clinical criteria of the American Academy of Sleep Medicine for the diagnosis of sleep bruxism [19].

With respect to the observational character of the present investigation no specific inclusion or exclusion criteria were determined. Regarding the application of psycho- 
metric instruments, the only limitation for a participation in this study was that each participant was required to have good German language skills.

\section{Design and instruments}

At the visit of either the TMD/OFPOC or the POC of the Department of Prosthodontics subjects completed two questionnaires. In total, the hand out of the questionnaires took place over a time period of seven months. Additionally, further descriptive data have been derived from their index cards. To assess sociodemographic and descriptive data (Table 1), a form had been prepared and was given to each subject.

For the assessment of individual somatic complaints each participant received a self-administered questionnaire to be completed by each individual. As shown in Table 2, it consists of 21 items assessing temporomandibular symptoms, dental complaints and details which have been frequently reported by patients from the TMD/OFPOC.

The Revised Symptom Checklist (SCL-90-R) is a worldwide used psychometric instrument with a high internal consistency and test-retest reliability [20-22] and in the present study it was applied in its standardized German version [23,24]. It consists of 90 items and determines the subjectively rated psychological distress that has been obtained during the past seven days. Respondents rated each item on a 5-point Likert scale (from "not at all" $=0$ to "extremely" = 4). These 90 items were summarized to nine subscales which measure different psychological symptoms (somatization, obsessive-compulsive, interpersonal sensitivity, depression, anxiety, hostility, phobic anxiety, paranoid ideation, and psychoticism). As a total score of psychological impairment, the Global Severity Index (GSI) was also applied.

In addition, to estimate the clinical relevance of the obtained results, the distribution of the GSI values of both patients from the POC and patients from the TMD/ OFPOC were compared with the previously determined and published GSI values of a normative sample, a sample of psychotherapeutic outpatients, and a sample of psychotherapeutic inpatients. The estimation of these reference values has been described in detail elsewhere [25]. Briefly, if the GSI values collected these three samples have been graphed, at a GSI value of 0.65 the distributional curve of the psychotherapeutic outpatient sample exceeded the curve of the normative sample. At a GSI value of 1.35 the distributional curve of the inpatient psychotherapeutic

Table I: Comparison of patients from the POC vs. patients from the TMD/OFPOC regarding sociodemographic and descriptive data (percentages shown in parentheses)

\begin{tabular}{|c|c|c|c|}
\hline & Patients from the POC $(n=65)$ & Patients from the TMD/OFPOC $(n=60)$ & $P$ \\
\hline Age (years) & $53.03 \pm 14.09$ & $43.45 \pm \mid 4.01$ & $* * * a$ \\
\hline Range (years) & 26 to 81 & 17 to 75 & \\
\hline Gender & $31 \mathrm{~F} ; 34 \mathrm{M}$ & $49 \mathrm{~F} ; \mathrm{II} M$ & $* * * b$ \\
\hline Number of children & $1.22 \pm 1.08$ & $1.02 \pm 1.08$ & n. s. ${ }^{c}$ \\
\hline Education (\%) & & & n. s. ${ }^{b}$ \\
\hline 10 years of school & $48(73.8)$ & $38(63.3)$ & \\
\hline 12 years of school & $7(10.8)$ & $9(15.0)$ & \\
\hline 13 years of school & $10(15.4)$ & $12(20.0)$ & \\
\hline No graduation & $0(0)$ & $\mathrm{I}(\mathrm{I} .7)$ & \\
\hline Marital status & & & n. s. ${ }^{b}$ \\
\hline Single & $14(2 \mid .5)$ & $16(26.7)$ & \\
\hline Married & $40(61.5)$ & $31(51.7)$ & \\
\hline Divorced & $5(7.7)$ & $8(13.3)$ & \\
\hline Widowed & $4(6.2)$ & $2(3.3)$ & \\
\hline Re-married & $2(3.1)$ & $3(5.0)$ & \\
\hline Residence (I missing) & & & n. s. ${ }^{b}$ \\
\hline Duesseldorf & $39(60.9)$ & $26(43.3)$ & \\
\hline Up to $25 \mathrm{~km}$ outside of Duesseldorf & $10(15.6)$ & $8(13.3)$ & \\
\hline More than $25 \mathrm{~km}$ outside of Duesseldorf & $15(23.4)$ & $26(43.3)$ & \\
\hline Duration of complaints (months) (3 missing) & $32.81 \pm 90.6$ & $43.50 \pm 80.41$ & $* * * c$ \\
\hline Type of referral (8 missing) & & & $* * \mathrm{~b}$ \\
\hline Referred by general dentist & $16(26.7)$ & $30(52.6)$ & \\
\hline Without referral & $34(56.7)$ & $14(24.6)$ & \\
\hline Miscellaneous & $10(16.7)$ & $13(22.8)$ & \\
\hline
\end{tabular}

n. s. $=$ not significant; $*=p<0.05 ; * *=p<0.01 ; * * *=p<0.001$

a Two-sample, two-tailed $t$ test; data are presented as means \pm standard deviations (SD)

b Chi-square test

c Mann-Whitney $U$ test; data are presented as means \pm standard deviations (SD) 
Table 2: Frequency distribution of several somatic complaints reported by patients from the POC and patients from the TMD/OFPOC (percentages shown in parentheses)

\begin{tabular}{|c|c|c|c|}
\hline & Patients from the POC $(n=65)$ & Patients from the TMD/OFPOC $(n=60)$ & $P$ \\
\hline Joint clicking & $13(20.0)$ & 46 (76.7) & $* * *$ \\
\hline Other TMJ sounds & $3(4.6)$ & $14(23.3)$ & ** \\
\hline Impaired mouth opening & $8(12.3)$ & $36(60.0)$ & $* * *$ \\
\hline Impaired mouth closing & $7(10.8)$ & $13(2 \mid .7)$ & n. s. \\
\hline Impaired chewing & $11(16.9)$ & $36(60.0)$ & $* * *$ \\
\hline Masticatory muscle fatigue & $5(7.7)$ & $19(31.7)$ & $* *$ \\
\hline Masticatory muscle stiffness & $4(6.2)$ & $20(33.3)$ & $* * *$ \\
\hline Extensive prosthodontic management prior to consultation & $48(73.8)$ & $33(55.0)$ & $*$ \\
\hline Extensive orthodontic management prior to consultation & $16(24.6)$ & $20(33.3)$ & n. s. \\
\hline Extensive surgical management prior to consultation & $21(32.3)$ & $19(31.7)$ & n. s. \\
\hline Extensive occlusal adjustment prior to consultation & $22(33.8)$ & $18(30.0)$ & n. s. \\
\hline Presence of habits & $4(6.2)$ & $9(15.0)$ & n. s. \\
\hline Nail biting & $2(3.1)$ & I (I.7) & n. s. \\
\hline Lip biting & $2(3.1)$ & $8(13.3)$ & $*$ \\
\hline Smoking & $13(20.0)$ & $10(16.7)$ & n. s. \\
\hline Tooth hypersensitivity & $23(35.4)$ & $22(36.7)$ & n. s. \\
\hline Disturbance of a single tooth & $8(12.3)$ & $14(23.3)$ & n. s. \\
\hline Pain upon wide mouth opening & $6(9.2)$ & $37(61.7)$ & $* * *$ \\
\hline Mouth dryness/burning mouth & $17(26.2)$ & $21(35.0)$ & n. s. \\
\hline Need of a specific position to correctly close the mouth & $9(13.8)$ & $26(43.3)$ & **** \\
\hline Self-assessment of treatment need & $29(44.6)$ & $54(90.0)$ & $* * *$ \\
\hline
\end{tabular}

For group comparisons Chi-square test was applied: n. s. = not significant; $*=p<0.05 ; * *=p<0.01$; *** $=p<0.00$ I

sample exceeded the curve of the psychotherapeutic outpatients. Concluding from these previously performed clinical group comparisons, in the present study the magnitude of psychological impairment of patients with a GSI value $\leq 0.65$ was assigned to the field of the normative sample, that of patients with a GSI value ranging $>0.65$ and $<1.35$ to the field of psychotherapeutic outpatients, and that of patients with a GSI value $\geq 1.35$ was seen in the field of psychotherapeutic inpatients, respectively.

\section{Missing data}

Generally, subjects that had more than one missing item in the form collecting sociodemographic and descriptive data and, additionally, one or more missing item in the questionnaire to determine individual somatic complaints were excluded. According to these criteria, 109 subjects were not included in the analysis. This drop-out sample consisted of 68 females and 41 males.

Finally, the remaining 125 subjects included 65 patients from the POC and 60 patients from the TMD/OFPOC. Thus, the average response rate amounted to $53.4 \%$. The data of two participants were not included, because the amount of missing items in the SCL-90-R compromised the calculation of the summary score. The maximum critical values of missing items still allowing the calculation of the subscales and the summary score, viz, the GSI, have been published elsewhere [24].

\section{Statistical analysis}

The statistical analysis was performed using the statistical software "SPSS" Version 14.0. Normal distribution was tested by using the Kolmogorov-Smirnov-Test along with an assessment of histograms. The analysis of group differences between patients from the POC and patients from the TMD/OFPOC was carried out for most of the predominantly qualitative variables (e.g., gender, education, items of the somatic questionnaire) by using Chi-square test. Independent samples $t$ test was only performed for age which was normally distributed as tested by Kolmogorov-Smirnov-Test. For all quantitative variables that were not normally distributed (e.g., duration of complaints, subscales of the SCL-90-R), differences were evaluated by means of the Mann-Whitney $U$ test. When using the Mann-Whitney $U$ test, the adequate statistical values are the mean ranks and the sum of ranks. However, to improve the comparability of the obtained results, data are presented as means and standard deviations (SD). For all statistical analyses an $\alpha$-error probability of $\mathrm{p}<0.05$ was adopted as the statistically significant level.

\section{Results}

As seen in Table 1, the comparison between patients from the POC and patients from the TMD/OFPOC revealed statistically significant differences with respect to age, gender, the duration of complaints, and the type of referral, whereas the evaluation of further sociodemographic vari- 
ables, such as education, marital status, and residence, showed no significant differences between both groups (Chi-square; $\mathrm{p}=\mathrm{n} . \mathrm{s}$. = not significant). Considering the career, patients from the TMD/OFPOC were significantly more ambitious than patients from the POC. To specify only the most relevant groups, $20 \%$ of patients from the POC and $43.3 \%$ of patients from the TMD/OFPOC were employed, $9.2 \%$ and $13.3 \%$ were in leading positions, $18.5 \%$ and $13.3 \%$ were housewives, and $30.8 \%$ and $8.3 \%$ were pensioners, respectively (Chi-square test; $\mathrm{p}<0.05$ ).

In 11 of the 21 items, the analysis of the distribution of somatic complaints revealed the following statistically significant differences (Table 2): patients from the TMD/ OFPOC reported more frequently joint sounds in general, an impaired mandibular movement or function (such as opening, yawning, chewing), masticatory muscle discomfort, problems to correctly bring maxillary and mandibular teeth together as well as oral habits like lip biting. Moreover, these patients stated that, immediately prior to the consultation, they did not receive as much extensive prosthodontic rehabilitation as patients from the POC. Finally, patients from the TMD/OFPOC unambiguously expressed the necessity of their complaints to be treated.

Considering psychological impairment due to distress perceived during the past seven days, the comparison of the two clinical groups did not show any differences between both groups (Table 3). In neither a subscale nor in the GSI statistically significant group differences were obtained. To estimate the clinical relevance of the recorded data, the above described reference values were applied (Table 4). In consideration of these reference values, no group specific differences were observed again. Even though data failed to reach the level of statistical significance, on the basis of the present findings, the GSI values of $31.3 \%$ of patients from the POC and $30.5 \%$ of patients from the TMD/OFPOC were clearly located above the GSI values that were obtained from a normative sample. In $21.9 \%$ of patients from the POC and in $22.0 \%$ of patients from the TMD/OFPOC, the extent of the determined psychological impairment reached values that were in the range of psychotherapeutic outpatients and, moreover, in $9.4 \%$ and in $8.5 \%$ values in the range of psychotherapeutic inpatients, respectively (Chi-square; $\mathrm{p}=$ n.s. $=$ not significant $)$.

\section{Discussion}

This prospective observational clinical study compared patients from the POC at the University of Duesseldorf with patients from the TMD/OFPOC at the same university regarding sociodemographic data, self-reported somatic complaints, and psychological impairment. As a major finding, the results clearly demonstrated that the degree of psychological impairment was similarly high in both groups. Interestingly, in approximately one third of the evaluated patients of both the POC and the TMD/ OFPOC the psychological impairment reached values that were located in the range of psychotherapeutic outpatients and psychotherapeutic inpatients. Indeed, this important finding supports numerous studies which revealed psychological characteristics in TMD patients [13-17,26-28]. Moreover, these results particularly stress the fact that patients from a POC represent a different group of patients showing a similar pronounced psychological impairment than do TMD patients.

Apart from dentistry, previous investigations have recorded the urban prevalence of psychiatric disorders in general practices. While depressive and anxiety disorders were detected in $15 \%$ to $25 \%$ of the patients from a general practice [29], surveys which have analyzed the entire prevalence of psychiatric disorders obtained values ranging from $21 \%$ to $52 \%$ [25,30-33]. With respect to the portion of psychologically impaired patients, it might be concluded that the present values established in the two

Table 3: Comparison of patients from the POC vs. patients from the TMD/OFPOC regarding the SCL-90-R subscales and the GSI values

\begin{tabular}{|c|c|c|c|c|c|}
\hline & \multicolumn{2}{|c|}{ Patients from the POC $(n=64)$} & \multicolumn{3}{|c|}{ Patients from the TMD/OFPOC $(\mathrm{n}=59)$} \\
\hline & Mean & SD & Mean & SD & $P$ \\
\hline Somatization & 6.97 & 8.36 & 8.71 & 7.78 & n. s. \\
\hline Obsessive-compulsive & 6.08 & 6.62 & 6.51 & 5.70 & n. s. \\
\hline Interpersonal sensitivity & 4.91 & 6.57 & 4.07 & 4.63 & n. s. \\
\hline Depression & 7.81 & 9.53 & 7.14 & 7.5 & n. s. \\
\hline Anxiety & 4.67 & 7.52 & 4.68 & 5.02 & n. s. \\
\hline Hostility & 2.69 & 4.16 & 2.36 & 2.63 & n. s. \\
\hline Phobic anxiety & 2.30 & 5.18 & 1.19 & 2.48 & n. s. \\
\hline Paranoid ideation & 3.59 & 4.51 & 2.98 & 3.71 & n. s. \\
\hline Psychoticism & 3.44 & 4.99 & 3.25 & 4.57 & n. s. \\
\hline GSI & 0.517 & 0.621 & 0.496 & 0.434 & n. s. \\
\hline
\end{tabular}

For group comparisons the Mann-Whitney $U$ test was applied: $n$. s. $=$ not significant; $*=p<0.05 ; * *=p<0.01 ; * * *=p<0.00$ I 
Table 4: Frequency distribution of the GSI values obtained for patients from the POC and patients from the TMD/OFPOC in consideration of the clinical reference values (percentages shown in parentheses)

\begin{tabular}{lcc}
\hline & Patients from the POC $(n=64)$ & Patients from the TMD/OFPOC $(n=59)$ \\
\hline GSI displayed according to the clinical groups & & \\
GSI<=0.65 (normative sample) & $44(68.8)$ & $41(69.5)$ \\
GSI $>0.65$ and $<1.35$ (psychotherapeutic outpatients) & $14(21.9)$ & $13(22.0)$ \\
GSI $>=1.35$ (psychotherapeutic inpatients) & $6(9.4)$ & $5(8.5)$
\end{tabular}

For group comparisons Chi-square test was applied: n. s. $=$ not significant; $*=p<0.05 ; * *=p<0.01 ; * * *=p<0.001$

university-based care centers are largely comparable to that derived from general practices.

Potential reasons for the magnitude of psychological impairment found in patients from a POC might be due to the reciprocal influences of tooth loss or denture wearing and psychological factors. For instance, some previous investigators suggested that the psychological response to tooth loss and denture wearing may be affected by patients' personality traits, sometimes more than by the technical quality of the dentures $[3,6]$. Conversely, tooth loss is reported to cause psychological impairment [3] and, moreover, previous investigators have shown that it contributes to a reduced quality of life [34].

The sociodemographic and reported somatic complaints data showed significant differences between the two groups, especially concerning age, gender, and most of the characteristic TMD symptoms. These findings were detected as a result of the sample composition. The unequivocal differentiation of the two groups by means of the reported somatic complaints, underlines the absence of any mixing between the two outpatient clinics. It might have been expected that patients suffering from tooth loss and, consequently, seeking prosthodontic management were on an average older than a group of patients from a $\mathrm{TMD} / O F P O C$. Interestingly, in contrast to the patients from the TMD/OFPOC the prosthodontic outpatients revealed a comparatively balanced gender distribution. Most of these patients sought care at the POC due to apparently somatic reasons such as the improvement of mastication or speech. The reasons differ from those reported by patients from the TMD/OFPOC. Potentially, such motives do not require a greater health awareness $[35,36]$ or specific experiences with the health care system [37] as they have been discussed to explain the pronounced female proportion in TMD patients.

Notwithstanding that groups differed with respect to age and gender, the comparison of patients of these two university-based care centers was found suitable for the following reasons: although previously several authors have discussed the interaction between psychological factors and tooth loss and/or subsequent prosthodontic manage- ment with removable dentures [3,5-7], to date, little is known of the extent of psychological impairment in patients seeking care for prosthodontic rehabilitation. Consequently, in a first exploratory approach patients collected from a POC should be investigated. Indeed, patients from a university-based care center represent a highly specific sample that may not easily be compared with patients from a general dental practice. However, if sociodemographic data of the patients seeking care at the POC of the Department of Prosthodontics at the University of Duesseldorf are compared with data derived from other German prosthodontic departments, they appear to be representative for these specific German care centers [34,38]. Regarding an adequate control group for the patients from the POC, a decision was made to investigate patients from a TMD/OFPOC at the same university due to diverse reasons. Firstly, these patients were recruited from a different university-based care center and, thus, represent a likewise highly specific sample. Secondly, many studies have underlined the contribution of psychological factors in the etiology of TMD [15-17,27,28]. This is also reflected by the currently highest standard for the diagnosis of TMD (i. e. RDC/TMD) due to the fact that it includes the assessment of specific psychological symptoms such as depression $[18,39]$. Therefore, TMD patients represent a group of patients who might be considered as a quite appropriate sample to compare the magnitude of psychological impairment.

The results of the present findings reproduce the typically clinical conditions and the complexity of the clinical reality [40] in German outpatient clinics. Keeping in mind that these clinics take part in university education programs and given the determined huge number of psychologically impaired patients from both the POC and the $\mathrm{TMD} / \mathrm{OFPOC}$, one might be in favor of asking to what extent these conditions find an adequate consideration in current dental education plans. In particular, in consideration of the increasing knowledge of the association between TMD and psychological factors, this demand has already been verbalized by different investigators many years ago [41-43]. Therefore, further investigations are required to substantiate the need of an increased consideration of psychological aspects in future dentistry. 


\section{Conclusion}

Within the limitations of this study, in approximately one third of the evaluated patients of both the POC and the TMD/OFPOC the psychological impairment reached values similar to those of psychotherapeutic outpatients and psychotherapeutic inpatients. Therefore, the present findings emphasize the need to intensify the integration of psychosomatic aspects into dentistry and, in particular, to add psychological considerations to future German education plans.

\section{List of abbreviations used}

(POC): Prosthodontic Outpatient Clinic; (TMD/OFPOC): TMD/Orofacial Pain Outpatient Clinic.

\section{Competing interests}

The authors declare that they have no competing interests.

\section{Authors' contributions}

$\mathrm{AH}$, US, and JK conceived the study design, MAO performed the statistical data analysis and wrote the manuscript, JGKH, RAD, SZ, and WHMR participated in the early preparation of the manuscript and contributed to write the revised version of the article. All authors read and approved the final manuscript.

\section{Acknowledgements}

The authors thank Ms D. Talbot, M.A., for her helpful comments on this paper.

\section{References}

I. Budtz-Jörgensen E: Restoration of the partially edentulous mouth - a comparison of overdentures, removable partial dentures, fixed partial dentures and implant treatment. J Dent 1996, 24:237-244.

2. Mazurat NM, Mazurat RD: Discuss before fabricating: communicating the realities of partial denture therapy. Part II: clinical outcomes. J Can Dent Assoc 2003, 69:96-100.

3. Allen PF, McMillan AS: A review of the functional and psychosocial outcomes of edentulousness treated with complete replacement dentures. J Can Dent Assoc 2003, 69:662.

4. Petridis H, Hempton TJ: Periodontal considerations in removable partial denture treatment: a review of the literature. Int J Prosthodont 200I, I 4:164-I72.

5. Carlsson GE: Clinical morbidity and sequelae of treatment with complete dentures. J Prosthet Dent 1998, 79: I7-23.

6. Diehl RL, Förster U, Sposetti VJ, Dolan TA: Factors associated with successful denture therapy. J Prosthodont 1996, 5:84-90.

7. McNaugher GA, Benington IC, Freeman R: Assessing expressed need and satisfaction in complete denture wearers. Gerodontology 200I, I8:5I-57.

8. De Jongh A: Clinical characteristics of somatization in dental practice. Br Dent J 2003, I 95: I5I-I54. discussion I45.

9. Schneider G, Wachter M, Driesch G, Kruse A, Nehen HG, Heuft G: Subjective body complaints as an indicator of somatization in elderly patients. Psychosomatics 2003, 44:91-99.

10. De Backer H, Van Maele G, De Moor N, Berghe L Van den: The influence of gender and age on fixed prosthetic restoration longevity: an up to 18- to 20-year follow-up in an undergraduate clinic. Int J Prosthodont 2007, 20:579-586.

II. American Academy of Orofacial Pain: Differential diagnosis and management considerations of temporomandibular disorders. In Orofacial Pain: Guidelines for Assessment, Diagnosis, and Management Edited by: Okeson JP. Chicago: Quintessence Publishing; |996:1 |3-184.
12. Yap AU, Chua EK, Hoe JK: Clinical TMD, pain-related disability and psychological status of TMD patients. J Oral Rehabil 2002, 29:374-380.

13. Yap AU, Chua EK, Tan KB, Chan YH: Relationships between depression/somatization and self-reports of pain and disability. J Orofac Pain 2004, I 8:220-225.

14. Yap AU, Tan KB, Chua EK, Tan HH: Depression and somatization in patients with temporomandibular disorders. J Prosthet Dent 2002, 88:479-484.

15. Carlson CR, Reid KI, Curran SL, Studts J, Okeson JP, Falace D, Nitz $A$, Bertrand PM: Psychological and physiological parameters of masticatory muscle pain. Pain 1998, 76:297-307.

16. Curran SL, Carlson CR, Okeson JP: Emotional and physiologic responses to laboratory challenges: patients with temporomandibular disorders versus matched control subjects. J Orofac Pain 1996, 10:141-150.

17. Wright J, Deary IJ, Geissler PR: Depression, hassles and somatic symptoms in mandibular dysfunction syndrome patients. J Dent 1991, 19:352-356.

18. Dworkin SF, LeResche L: Research diagnostic criteria for temporomandibular disorders: review, criteria, examinations and specifications, critique. J Craniomandib Disord 1992, 6:301-355.

19. American Academy of Sleep Medicine: The International Classification of Sleep Disorders, Revised: Diagnostic and Coding Manual 2nd edition. Westchester: American Academy of Sleep Medicine; 2005.

20. Derogatis LR: SCL-90-R, Administration, Scoring, and Procedures Manual for the R(evised) Version Baltimore: John Hopkins University, School of Medicine; 1977.

21. Derogatis LR: SCL-90-R, Administration, Scoring, and Procedures ManualII for the R(evised) Version and Other Instruments of the Psychopathology Rating Scale Series Towson: Clinical Psychometric Research; 1983.

22. Derogatis LR, Lipman RS, Covi L: SCL-90: an outpatient psychiatric rating scale - preliminary report. Psychopharmacol Bull 1973, 9:13-28.

23. Franke G, Stäcker KH: Reliabilität und Validität der SymptomCheck-Liste (SCL-90-R; Derogatis, 1986) bei Standardreihenfolge versus inhaltshomogener Itemblockbildung. Diagnostica 1995, 41:349-373.

24. Franke GH: SCL-90-R: Die Symptom-Check-Liste von Derogatis-Deutsche Version Göttingen: Beltz Test Gesellschaft; 1995.

25. Tress W, Kruse J, Heckrath C, Schmitz N, Alberti L: Psychogenic Disorders in Primary Care. Z Psychosom Med Psychoanal 1997, 43:2 II-232.

26. Celic R, Panduric J, Dulcic N: Psychologic status in patients with temporomandibular disorders. Int J Prosthodont 2006, 19:28-29.

27. Grossi ML, Goldberg MB, Locker D, Tenenbaum HC: Reduced neuropsychologic measures as predictors of treatment outcome in patients with temporomandibular disorders. J Orofac Pain 2001, I 5:329-339.

28. LeResche L, Mancl LA, Drangsholt MT, Huang G, Von Korff M: Predictors of onset of facial pain and temporomandibular disorders in early adolescence. Pain 2007, I 29:269-278.

29. Barrett JE, Barrett JA, Oxman TE, Gerber PD: The prevalence of psychiatric disorders in a primary care practice. Arch Gen Psychiatry 1988, 45: 1100-1106.

30. Dilling H, Weyerer S, Enders I: Patienten mit psychischen Störungen in der Allgemeinpraxis und ihre psychiatrische Überweisungsbedürftigkeit. In Psychiatrische Epidemiologie Edited by: Häfner H. Berlin: Springer; 1978: I35-160.

31. Üstün TB, Sartorius N: Mental Illness in General Health Care Chichester: Wiley; 1978.

32. Zintl-Wiegand A, Cooper B: Psychische Erkrankungen in der Allgemeinpraxis: eine Untersuchung in Mannheim. Nervenarzt 1979, 50:352-359.

33. Zintl-Wiegand A, Cooper B, Krumm B: Psychisch Kranke in der Ärztlichen Allgemeinpraxis Weinheim: Beltz; 1980.

34. John MT, Slade GD, Szentpetery A, Setz JM: Oral health-related quality of life in patients treated with fixed, removable, and complete dentures I month and 6 to 12 months after treatment. Int J Prosthodont 2004, I 7:503-5 I I.

35. Bush FM, Harkins SW, Harrington WG, Price DD: Analysis of gender effects on pain perception and symptom presentation in temporomandibular pain. Pain 1993, 53:73-80.

36. Randolph CS, Greene CS, Moretti R, Forbes D, Perry HT: Conservative management of temporomandibular disorders: a post- 
treatment comparison between patients from a university clinic and from private practice. Am J Orthod Dentofacial Orthop 1990, 98:77-82.

37. Krogstad BS, Jokstad A, Dahl BL, Vassend O: The reporting of pain, somatic complaints, and anxiety in a group of patients with TMD before and 2 years after treatment: sex differences. J Orofac Pain 1996, 10:263-269.

38. Szentpetery AG, John MT, Slade GD, Setz JM: Problems reported by patients before and after prosthodontic treatment. Int J Prosthodont 2005, 18: |24-|3|.

39. Dworkin SF, Sherman J, Mancl L, Ohrbach R, LeResche L, Truelove E: Reliability, validity, and clinical utility of the research diagnostic criteria for Temporomandibular Disorders Axis II Scales: depression, non-specific physical symptoms, and graded chronic pain. J Orofac Pain 2002, 16:207-220.

40. Groten M, Janda R, Latta M: Clinical Investigations of Medical Devices in Dentistry - Specification, Interpretation, and Practical Guidance London: Quintessence Publishing; 2004.

4I. Johnke G: Klinische Psychologie in der zahnärztlichen Praxis Hannover: Schlütersche; 1997.

42. Müller-Fahlbusch H: Ärztliche Psychologie und Psychosomatik in der Zahnheilkunde. In Dent Praxis Edited by: Körber E, Klaiber B. Stuttgart: Thieme; 1992.

43. Neuhauser W: Psychosomatik und Zahnheilkunde (II). Bayer Zahnärztebl Mitt Kassenzahnärztl Ver Bayerns 1985, 24:I8-20.

Publish with Bio Med Central and every scientist can read your work free of charge

"BioMed Central will be the most significant development for disseminating the results of biomedical research in our lifetime. "

Sir Paul Nurse, Cancer Research UK

Your research papers will be:

- available free of charge to the entire biomedical community

- peer reviewed and published immediately upon acceptance

- cited in PubMed and archived on PubMed Central

- yours - you keep the copyright

Submit your manuscript here:

http://www.biomedcentral.com/info/publishing_adv.asp
BioMedcentral 